\title{
LA ROPA COMO ACULTURACIÓN EN LA AMAZONÍA PERUANA*
}

\author{
Peter Gow
}

Este artículo examina el significado de la ropa para los yine, un pueblo arawak del Bajo Urubamba, y de los cambios de estilos de vestir ocurridos en su historia durante los últimos siglos de contacto con la colonización. Este acercamiento histórico tiene dos consecuencias. Primero, sugiere que los yine piensan sobre la ropa como algo que señala la alteridad. Los yine continuamente toman la ropa de otros seres, ya sea pueblos vecinos, gente blanca, o jaguares. Segundo, sugiere que lo que nosotros llamamos "aculturación" es mas bien una concepción indígena amazónica sobre los procesos históricos en marcha. Los pueblos amazónicos no están queriendo adquirir la "cultura" del otro, porque la "cultura" es ajena a sus cosmologías perspectivistas. La "aculturación" es, por lo tanto, una descripción literal superficial de las cosmologías perspectivistas en acción histórica.

This paper examines the meaning of clothing for the Yine, an Arawakan people of the Low Urubamba, and the changes in style occurred during the last centuries of contact with colonization. This historic approach has two main consequences. First, it suggests that the Yine think of clothing as something indicating alterity. They are continually borrowing clothing styles from other beings, including their neighbours, white people, or jaguars. Secondly, it suggests that what we call "acculturation" is in fact an indigenous Amazonian conception about ongoing historical processes. Indigenous Amazonians do not wish to acquire other people's "culture", because "culture" is alien to their perspectivistic cosmologies. Therefore, "acculturation" is a superficial literal description of perspectivistic cosmologies in historic action.

Traducido del inglés por Luisa Elvira Belaunde. 
En 1961, Peter Matthiessen, escritor de literatura de viaje americano, viajó rió abajo por el Urubamba, en la Amazonía peruana. Sobre un gran poblado yine escribió lo siguiente:

Llegamos a Sepaluua al principio de la tarde, y fuimos saludados desde la orilla por un bando mixto de piros, amahuacas y machiguengas. Pero, esta gente no lleviaba puesta sus ropas tribales, y, por lo tanto, eran más o menos indistinguibles. El lugar parecía ser menos un pueblo indigena que una feria a campo abierto, lo que, en efecto, era. Al decir esto, no quisiera expresar ninguna desaprobación del padre Manulel Diez y de su alegre personal de hermanos y hermanas, ni tampoco de los otros bondadosos dominicos que mantuvieron en pie a nuestros cuerpos y almas por casi una semana. Todos son gente buena, haciendo un buen trabajo, a pesar de lo desagradable que los efectos de dicho trabajo pueda parecerle a gente como yo. Es muy triste ver que al carácter indicidual de estos indios está desapareciendo rápidamente bajo la acción del gran mezclador del hombre blanco, sagrado o no, no importa que tan beneficioso este pueda ser para la barriga, o la salvación, de los bravos. Los pobladores de Sepalutia yt $n 10$ son más indigenas, sino peruanos ignorantes e indigentes; y sus primos en e interior de las quebradas, con su cabello largo y su pintura, tienen una aparien:cit mejor. En Sudamérica, con unas cuantas excepciones, la tribu que entra en contacta completo con el hombre blanco, bajo los términos del hombre blanco, tiene, tal ter medio siglo de existencia por delante (1962:211).

"Piro" es el apodo cariñoso con el que los konibo llaman a los yine, y que fuz muy usado por otros pueblos y por ellos mismos, hasta que las federaciones políticas indígenas insistieron en usar la palabra "humano" como su verdadero nombre. E informe de Matthiessen, aunque parezca evidente o banal, pertenece a una larga compleja tradición intelectual. Parafraseando a Gombrich con respecto a la pintura (1960), los libros de viaje le deben mucho más a otros libros de viaje que a los hechos ocurridos durante los viajes. En este caso, el informe de Matthiesesen pertenece a una tradición del pensamiento sobre el progreso de la civilización y su relación cur la naturaleza, tanto humana como otra, que se consolidó en los Estados Unidos ere siglo XIX, y se expandió hacia afuera. El sentimiento que el progreso, la expansi de la civilización, es necesariamente destructivo de la naturaleza y la diversid cultural es central en esta tradición. Más cultura significa menos naturaleza, y civilización equivale a menos diversidad cultural. La conexión con las teorías de la modernidad es obvia.

Con respecto a este punto, debo manifestar un interés propio. Estoy de acuerát con Matthiessen, puesto que su reacción ante la apariencia visual de los puebindígenas del Urubamba era, y en cierta medida, sigue siendo igual a la mía. Esto debe, seguramente, a que tanto Matthiessen como yo somos los productos de $=$ historia similar, que considera a ciertos juicios estéticos como axiomáticos. Lo qe nos diferencia es que yo he pasado 25 años involucrado con los pueblos indíger 
de esa parte de la Amazonía peruana, intentando conocer lo que piensan sobre las cosas. Matthiessen pasó un periodo de tiempoigual, y hasta mayor, pensando sobre otras cosas, jgualmente importantes.

Me gustaría contrastar la cita de Matthiesen con otra, proveniente de un mito que me fue contado hace veinticinco años por Artemio Fasabi, líder del poblado de San Clara, que se encuentra rió abajo de Sepahua, y que es la comunidad en donde conduje la mayor parte de mi trabajo de campo. El me contó:

Hace tiempo, la gente dice que habia un hombre que era el unico hijo de una mujer sin esposo. Para mantenerla, se iba al monte, se sacaba su cushma, y se convertía en un jaguar. Así, se paseaba por la selva matando mitayo. Cuando acaba, se ponía su cushma de vuelta y se convertía humano otra vez, y llevaba el mitayo a su madre. Le llezaba huangana, venado, majaz, de todo.

Cushma es la palabra del quechua regional que designa lo que los yine llaman mkalu, una túnica de algodón, tejida a mano y pintada. La mención en el texto de "huangana, venado, majaz, de todo" indica que las proezas de cacería del protagonista son muy deseadas por los yine. El mito continúa contando el origen de la brujería, que se debió a la incapacidad de la gente antigua de matar ese "hombre-jaguar".

Claramente, para Artemio Fasabi, el narrador de este mito, la ropa tiene otro significado que el que tenía para Matthiessen. Fasabi, nacido en 1947, cursó la escuela segundaria en Sepahua y, muy probablemente, era uno de los que estaban en ese "bando mixto de piros, amahuacas y machiguengas" que le dio la bienvenida a Matthiessen. En este articulo, abordo la naturaleza de las diferencias de ideas y prácticas sobre la ropa entre gente como Artemio Fasabi y Peter Matthiessen.

\section{La literatura de viaje}

En la literatura de viaje sobre la Amazonía, la transformación de la ropa, y los estilos de arte corporal tradicionales, en ropa usada por "gente blanca" es presentada como un hecho inevitable, y como una evidencia de la "pérdida cultural" que acompaña el aumento del contacto con el mundo civilizado. Aunque los etnógrafos no concuerden con las primicias de estos argumentos, por lo general, no han intentado refutarlos. Por cierto, la mayoría de los etnógrafos sólo han escrito anotaciones sobre los cambios de vestimenta, sin desarrollar un análisis sobre sus observaciones (ver Hugh-Jones 1992; Veber 1996; Ewart \& Conklin ). El que los pueblos de la Amazonía estén rápidamente adoptando ropa occidental es, pues, una banalidad sin análisis de la literatura sobre la región. Y cuando este proceso es estudiado, lo es bajo el término de "aculturación", concebido como una fragilidad de las culturas amazónicas ante la expansión occidental; a pesar de que un concepto como "aculturación" vuelve estas transformaciones social e históricamente opacas. 
El concepto de "aculturación" cubre por lo menos tres niveles distintos de cambio: (a) un cambio de términos (entre modos tradicionales de decoración corporal, y modos nuevos y alienados); (b) un cambio de relaciones entre términos (entre los significados tradicionales y los sentidos modernos de la decoración corporal); y (c) un cambio de sistemas de relaciones entre términos (entre sistemas de producción de significado, cada cual concebido como global y auto-suficiente, pero también, como variaciones transformacionales de potencialidades humanas). Tal vez pueda ser que la vestimenta como aculturación sea un hecho en la Amazonía peruana, pero no es una teoría antropológica sobre este hecho.

Este ensayo intenta investigar este fenómeno valiéndose de una teoría etnográfica. Por este término, que le debo a Marcio Goldman del Museo Nacional de la Universidad Federal de Río de Janeiro (com. pers.), me refiero al desarrollo antropológico de las categorías usadas por mis informantes yine como instrumentos analíticos claves para comprender lo que están haciendo. Una teoría etnografica, claramente, no es un "relato cultural", porque usa categorías locales de maneras en que los pobladores locales no lo harían, o por lo menos, en que no lo hacen. Tampoco es, estrictamente, una teoría antropológica, porque, necesariamente, utiliza categorías ajenas al pensamiento antropológico. Las teorías etnográficas son particularmente apropiadas en situaciones como la presente, en donde los analistas pueden estar tan metidos en una sola versión de un fenómeno que pueden seriamente correr el riesgo de dejarse engañar por sus propias categorías locales, las cuales, al mismo tiempo, los fascinan y los desorientan.

\section{Teorizando el cambio de ropa}

Los estilos de vestir yine, así como sus estilos de arte corporal, de manera general, pueden ser examinados con relación a la cosmología perspectivista de Viveiros de Castro (1998) (véase también Rivière 1994, Lima 1999 y Gow 2001). Viveiros de Castro caracteriza a las cosmologías perspectivistas como multinaturalistas, contrastándolas con las cosmologías occidentales multiculturalistas. Las cosmologías multiculturalistas afirman la unidad de los cuerpos (todos construidos con las mismas cosas y de las mismas maneras) y la multiplicidad de las almas, las mentes y las culturas. En cambio, las cosmologías multinaturalistas, como las cosmológicas perspectivistas amazónicas, operan por medio de la unidad de la mente y el alma de todas las entidades, y la multiplicidad de sus cuerpos. El cuerpo, no la mente, es la fuente de la diferenciación entre tipos de entidades. El cuerpo es una serie de aparatos afectivos a través de los cuales la mente percibe el mundo. Viveiros de Castro sostiene que el cuerpo, en las cosmológicas perspectivistas, no es una base natural, como en las cosmologías multi-culturalistas, sino algo más próximo a una máscara o una vestimenta. Obviamente, el argumento de Viveiros de Castro juega sobre los significados que nosotros, multiculturalistas, le atribuimos a las mentes, los cuerpos, las máscaras y las ropas. No nos puede llevar directamente al significado que tienen las mentes, los cuerpos, las máscaras y las vestimentas para los multinaturalistas. 
Por ejemplo, en una cosmología multi-culturalista, una máscara, o una pieza de vestir, tapa la visión de un cuerpo, haciéndolo ver como algo distinto de lo que realmente es - la máscara o la pieza de vestir expresa y se refiere a la multiplicidad de las mentes y las culturas de los usuarios. En una cosmología multinaturalista esto no puede suceder, porque todas las mentes y todas las culturas son la misma. La diversidad reside en el cuerpo. Viveiros de Castro sostiene que las máscaras, las piezas de vestir y los atributos corporales, deben de ser concebidos como más próximos de nuestra idea de una malla de buceo: es decir, un instrumento para moverse en un medio ajeno al normal. Una malla para bucear le permite a los humanos operar como criaturas acuáticas de manera propia. Una malla de buceo, literalmente, le da al cuerpo humano atributos de pescado o de cetáceo; y Viveiros de Castro sostiene que lo mismo sucede con las máscaras y las vestimentas en las cosmologías multinaturalistas.

El perspectivismo nos da un instrumento poderoso para comprender el vestir yine en términos de cómo se ven las cosas. Al narrar el mito de origen del tejido, Juan Sebastián, dice:

Antes de saber hilar, sólo golpeaban las bolitas de algodón y luego pintaban la plancha de algodón con achiote o con otros líquidos teñidores. Se dice que de una distancia, las personas vestidas así, tenían la apariencia de tener el cuerpo rojo (ser-pozvaa), pero de cerca parecía tela, cuando sólo era una plancha de algodón pintado (Pérez et al. 1974:119, 126-7).

La cuestión aquí no es simplemente "como se ven las cosas", ni si es que la ropa es una máscara o un disfraz. La palabra ser-pozvaa traducida por "cuerpo rojo", viene de la raíz - poiva, que se refiere a algo que está envuelto en otra cosa (Matteson 1965:328). La misma raíz genera la palabra popozvalu (o popozulu), que es definida por el Diccionario Piro como "una persona vestida; un animal antes de ser pelado o desplumado" (Nies 1986?176-7). Un animal pelado, o desplumado, no es, de ninguna manera, una expresión más pura de su especie que un animal antes de ser puesto a muerte. De igual manera, un humano vestido no es un humano disfrazado o enmascarado. Un humano vestido es un humano completo, enteramente especificado.

\section{Un relato fenomenológico del vestir yine}

El análisis de Viveiros de Castro no puede ser reducido a una oposición o una dialéctica entre una apariencia externa engañosa y un interior escondido, pero más genuino. En su Teoría GUT (2001), el autor señala que la relación entre la apariencia y lo que la apariencia cubre está marcada por un desequilibrio perpetuo, una frase tomada en préstamo de Lévi-Strauss (1995). Por ejemplo, se puede decir que, para los yine, la vestimenta, mkalu, cubre el cuerpo, -mane, pero, a su vez, este último término es concebido como lo que cubre un "alma" interior, generalmente escondida. 
Es más, el alma es a su vez, la apariencia engañosa de gipnachri, "el cadáver, hueso, demonio", que después de la muerte de alguien y de su podredumbre en la tumba, puede ser visto por los vivos como un esqueleto de ojos ardientes. Pero, los que toman el poderoso alucinógeno gayapa dicen que ven al gipnachri, de los muertos y de los vivos, como gente joven y bien vestida. Hasta aquí llega mi conocimiento, y tal vez también el de los yine, sobre el perpetuo desequilibrio entre la apariencia y lo que es cubierto por la apariencia; pero la regresión es potencialmente infinita ${ }^{1}$. Hay que mantener estas ideas en mente durante la discusión a seguir.

Todos los yine que viven en el río Urubamba usan lo que ellos llaman kajitu mkalu, "ropa de blancos", o makiu potu, "ropa legitima". Esta ropa es específica para cada género: camisas, polos, pantalones y shorts para los hombres y los muchachos; y vestidos, blusas, polos y faldas o bermudas, para las mujeres. La mayoría de la ropa es comprada a los comerciantes de Atalaya y Sepahua. Algunas mujeres mayores hacen sus propios vestidos con tela comprada; y una pequeña cantidad de ropas de segunda mano, traídas de Estados Unidos y Europa, usada principalmente por los ancianos y los niños, es adquirida en las tiendas de los misioneros. Esta ropa es útil, pero no es particularmente deseable.

Los yine consideran que la ropa debe ser comprada. Puesto que la mayoría de! dinero es ganado por los hombres, la ropa es comprada por los hombres y entregada a los demás, o comprada por las mujeres con el dinero dado por los hombres. El dinero es la propiedad exclusiva de su dueño: Las exigencias sobre el dinero de los demás se expresan en términos de "amor" y de "cuidados", pero nunca en términos de una propiedad múltiple. Casi todas las prendas yine pueden ser especificadas en términos de quien las compró, quien dio el dinero, y quien se la entregó a quien. La ropa yine es comprada con el dinero ganado casi exclusivamente por los hombres, aunque no son necesariamente los hombres quienes la compran, y la dan de regalo directamente a personas especificas.

Los yine rara vez comparten ropa con los demás. Ni siquiera entre personas unidas por relaciones íntimas (entre hermanas, por ejemplo). Tampoco le dan su ropa a los demás cuando la han usado. Hasta los niños pequeños saben qué prenda en las pilas de ropa les pertenece, y se rehúsan a usar hasta la ropa de sus hermanoミ de mismo género. Esta negativa también es observada por los adultos. En efecto, conversando con niños y adultos queda claro que, para los yine, la ropa es la forma primaria del objeto de posesión. Es probable que la ropa sea el único tipo de objeto de propiedad de los niños pequeños; y la ropa es un tema clave de las historias contadas por los adultos sobre sus recuerdos de los cuidados que recibieron durante la infancia. Cuando el ciclo de vida de una persona llega a su fin, todas sus ropas

El acercamiento de Viveiros de Castro sugiere una dinámica conceptual diferente entre las idez:amazónicas y melanesias sobre la apariencia engañosa y escondida de la realidad, tan bien descriz en la literatura etnográfica. 
son destruidas después de la muerte. Y si por alguna razón, no se dispone del cadáver para velarlo (lo cual es común en caso de muerte por ahogamiento, un hecho, a su vez, bastante común), la ropa del difunto puede volverse un substituto de su cuerpo.

Como he mencionado, este tipo de ropa es llamada kajitu mkalu, "ropa de blanco", o mkalu potu, "ropa legitima". La palabra yine potu, así como la palabra en castellano ucayalino "legítimo", indica que un objeto es real. Algo "real" es el ejemplar mejor y más fuerte de una cierta categoría. Con una excepción importante, los objetos que los yine consideran "reales" están imbuidos de nociones sobre poder supernatural y seres ajenos.

Estas cosas "reales", desafían la capacidad de los yine de imaginarse cómo pueden haber sido hechas. Al ver objetos cómo un reloj de pulsera, una radio o un avión, los yine no cuentan con elementos para entender como estas cosas fueron hechas. Una importante excepción son los "humanos". Los yine se consideran a sí mismos yine potu, "humanos legítimos", el mejor y más fuerte ejemplar de la categoría. El conocimiento de cómo hacer yine potu, "humanos legítimos", es un conocimiento de la vida diaria yine.

La "ropa de la gente blanca", o "ropa legítima", se opone a las formas de vestir de las viejas generaciones muertas de la gente yine, llamadas mkalu, la larga túnica tejida usada por los hombres, y las faldas tejidas de algodón de las mujeres, mkalnama, "vestido de boca/vagina". Estas vestimentas todavía se hacen, pero son raramente usadas: la mayoría es hecha para ser usada en las (actualmente) pocas celebraciones de los rituales de iniciación de las muchachas, o para ser intercambiadas con gente blanca ${ }^{2}$. También pueden ser utilizadas en la vida diaria para calentarse cuando el clima está más frío de lo habitual, o como ropa de cama; pero de ser usadas para el día a día suscitaría comentarios desfavorables, o ridículos ${ }^{3}$.

\section{Cambio}

¿Qué significa para los yine llevar "ropa de blancos"? ¿Significa que se están volviendo blancos? ¿Consideran ellos que se están volviendo blancos? ¿Acaso esperan que al usar esta ropa se van a volver blancos? Este es el tipo de preguntas colocadas por el informe de Matthiessen, y también por mi reacción inicial y por la reacción estética aún vigente entre muchos hacia la apariencia de los yine.

Primero, los yine no usan ropa de blancos para convertirse en blancos. La palabra yine kajitutachri, "el que acostumbra actuar como un hombre blanco", es un insulto grave. Los yine temen y desprecian a la gente blanca debido a su rabia, su

\footnotetext{
2 Las mujeres yine expresan su desilusión con la escasa demanda de sus productos entre los blancos, y sin duda, producirian mucha más ropa tejida si su trabajo fuese más económicamente rentable. Cabe anotar que la mayoría de la gente yine mantiene contacto bastante regular con gente asháninka que usa túnicas de algodón como ropa de diario.
} 
violencia y su mezquindad. No tienen ningún interés en convertirse en gente blanca, o en absorber su "cultura" o sus "maneras de ser".

El valor central de la gente yine es gzuashta, "viviendo bien", viviendo en comunidades íntimas y apacibles, llenas de parientes que generosamente comparten comida y ayuda. "Vivir bien" es la manifestación colectiva del nshinikanchi, "memoria, amor, mente, pensar", de cada miembro de la co-residencia. El nshinikanchi de una persona se desarrolla en reciprocidad a los actos de cuidado recibidos durante la infancia: el pensamiento de un niño hacia los demás es generado por medio de la comida y la atención que le es prodigada, y por la interacción buen-humorada. Nshinikanchi es una disposición específica, y no generalizada: los cuidados dados por otra persona son dados de vuelta recíprocamente a esa persona específica. Los yine no sienten obligación ninguna de ayudar a gente con las que no están relacionados, y dicen que los yine son las personas más pensantes e inteligentes del mundo porque, de costumbre, quienes los tratan de la manera más gentil son justamente otros yine. La gente blanca, en cambio, es descrita como mshinikatu, "olvidadiza, sin amor, sin mente, sin pensamiento". Kajitutachri, "el que acostumbra actuar como un hombre blanco", es un insulto, justamente porque lleva esta carga desagradable.

Cabe anotar que, en el pasado, los yine capturaban y compraban a los niños de los pueblos vecinos, $y$, hasta el día de hoy, siguen capturando y criando a las crías de los animales salvajes. Si reciben buenos cuidados, al crecer estos niños extranjeros y estas mascotas demuestran adquirir buenos pensamientos y capacidades, al igual que la gente yine. En cuanto a los antropólogos extranjeros que los visitan, mi propia experiencia de cambio personal, les permitió cerciorarse que también es posible criarnos de igual manera.

\section{Mgenoklu, jaguares}

Dadas las asociaciones extremadamente negativas atribuidas a la gente blanca, y el hecho que los yine consideran que la gente blanca invierte sus valores y formas de ser fundamentales, ¿a qué se debe que quieran usar la ropa de la gente blanca? Una respuesta reside en su relación con lo que podríamos llamar su "ropa tradicional", pero que según los yine debería ser llamada "ropa de los antiguos". Por cierto, los yine le tienen temor a su "ropa tradicional" porque, a su parecer, esta ropa los hace ver como jaguares. Como he mostrado en otro artículo, la asociación entre la "ropa tradicional" y los jaguares es, al mismo tiempo, abierta y omnipresente en el pensamiento yine.

Los yine temen a los jaguares por tres principales razones: por el peligro mortal que implican para la gente; por su espantosa belleza; y por su soledad. Los jaguares son depredadores de los grandes mamíferos terrestres, incluso de humanos, sumamente adaptados al medio, por lo que, en efecto, son sumamente peligrosos. 
Su peligrosidad es encapsulada en su belleza hipnótica: los relatos de encuentros con jaguares nunca dejan de mencionar el asombro estético causado por su apariencia. $Y$ finalmente, los jaguares son, por lo general, solitarios. Son particularmente asustadores cuando uno se encuentra inesperadamente con uno de ellos a solas, por ejemplo, cuando uno está desyerbando la chacra en silencio. Y mitológicamente, la soledad de los jaguares es una precondición de la sociedad humana. La socialidad humana surgió de la destrucción de la sociedad jaguar, cuando el héroe creador Tsla y sus hermanos mataron a todos los "jaguares que vivían en grupo", a excepción de una vieja hembra preñada.

El estilo de "la ropa de los antiguos", las túnicas de algodón y faldas pintadas con diseños yonchi, hacía que la gente se viese como jaguares (mgenklu pixkalutu). En su expresión más fuerte, recién tejida y pintada, con los diseños negros relucientes sobre el fondo blanco del algodón nuevo, "la ropa de los antiguos" era utilizada solamente para lidiar con relaciones potencialmente conflictivas. La más importante de estas era el kigimazulo, el ritual de iniciación de las muchachas púberes, cuando todos los yine se reunían a celebrar la entrada de la niña a la condición de mujer. Esta congregación de "todos los yine a lo largo del río" acarreaba el encuentro de mucha gente con historias pasadas de malas relaciones; gente unida no tanto por sus "buenos pensamientos" de los unos hacia los otros, sino por su "olvido". Estas malas relaciones incluían desde sentimientos de abandonado por sus parientes cercanos, hasta recuerdos de peleas graves, y sospechas o acusaciones abiertas de brujería. En dichas circunstancias, los yine procuraban mostrarse a los demás bajo la forma de jaguares.

Se puede considerar que la "ropa de los antiguos" recién estrenada es un uso de un "afecto jaguar", siguiendo el concepto propuesto por Viveiros de Castro. Es decir, un aspecto de lo que haceque un jaguar sea jaguar, su forma visual, es retomado por un no-jaguar como un instrumento de intimidación. Anfitriones e invitados se ven los unos a los otros como jaguares, y experimentan el temor que los jaguares le causan a los humanos. Esta apariencia temible es, entonces, subvertida durante el proceso ritual a la medida en que los anfitriones le sirven "comida legítima", nika potu, a sus invitados, es decir carne cocida, vegetales y masato, y no mgenoklu nika, "comida de jaguar", que es carne cruda. Siguiendo la secuencia del ritual, al comenzar la festividad, la carne cocida y los vegetales servidos por los anfitriones afirman que estos "jaguares" son en realidad parientes; después, el masato subvierte esta identificación al emborrachar a todos y, por lo tanto, volverlos afines potenciales entre sí. El ritual termina cuando la afinidad potencial es transformada en una afinidad real, diaria, al establecerse el matrimonio de la muchacha iniciada con uno de los invitados.

Como acontecimientos, los rituales yine están marcados por lo "nuevo" (gerotu). El ritual de iniciación se concentra en el surgimiento de una "nueva mujer", y toda la 
parafernalia ritual, especialmente la ropa de los participantes, es nueva. Esta novedad es, con respecto a la apariencia de la iniciada así como con respecto a la ropa de los participantes, marcada por un fuerte contraste de colores: la intensidad jaguar de magnífica belleza. En cambio, la transición entre este acontecimiento ritual y la vida diaria que le sigue está marcada por un proceso de gitlika, "desgaste, madurez". Esto se manifiesta, en particular, en el desgaste y el desvanecimiento progresivo del nso, de la pintura facial y corporal de huito (Genipa americana), durante el transcurso del ritual. Este "desgaste, madurez" sucede en paralelo a la transformación de las relaciones entre anfitriones e invitados, desde la extrema hostilidad inicial, hasta la afinidad diaria, intensamente respetuosa después del matrimonio. De igual manera las ropas hechas especialmente para el ritual "se desgastan y maduran" con el pasadel tiempo, con los lavados vigorosos y las vueltas a pintar, hasta convertirse en ropas "viejas y feas", usadas en el día a día.

La vida diaria es el producto de la exitosa negociación de la diferencia socia extrema y temible, y de su transformación en gwashta, "viviendo bien". Las calidades diarias de "viviendo bien" están caracterizadas por complejas calidades estéticas pero no por las amplificaciones estéticas extremas de "verse como jaguares". Ut afecto-jaguar, el uso de partes del cuerpo del jaguar para fines instrumentales, $\underset{\varepsilon}{\sigma}$ apropiado para los rituales, pero no lo es para la vida diaria. Esta es, a mi parecer, th fuerza del mito que Artemio me contó sobre un "hombre-jaguar". El problema dè "hombre-jaguar" no era que utilizaba un afecto-jaguar, sino que lo utilizaba en in vida diaria, suscitando los celos de sus vecinos de comunidad, y por lo tanto subvirtiendo el "viviendo bien". Estos celos hicieron que los demás buscasen descub= la naturaleza de su éxito, y lo expusiesen como jaguar. En efecto, el "hombre-jaguar" trataba a la vida diaria de la manera como los yine tratan a los acontecimientos rituales: el "hombre-jaguar" usaba ropa yine, un afecto-humano, para establecer sus relaciones diarias con su madre de la manera como los yine usan afectos-jagu= para establecer relaciones rituales entre ellos.

La historia de Artemio era una "historia de los antiguos", un mito. En conclusión de su exposición sobre la cosmología perspectivista, Viveiros de Cas:señala que:

... el perspectivismo amerindio tiene un punto de desvanecimiento, por asi decir, en donde las diferencias entre los puntos de vista son a la vez anuladas y exacerbad.:mito, que de esta manera adquiere el carácter de un discurso absoluto. En el mi cada especie de ser aparece a las demás como se aparece a si misma (como humar al mismo tiempo, continía mostrando su naturaleza distintiva y definitiva. animal, planta o espíritu). En cierto sentido, todos los seres que pueblan la mitoiogson chamanes, lo cual, en efecto, es explicitamente afirmado por algunas culturt amazónicas ... El mito habla de un estado de ser en donde los cuerpos y los nombre las almas y los afectos, el yo y el otro se interpenetran, sumergidos en un mism 
medio pre-subjetivo y pre-objetivo - un medio cuya finalidad es precisamente lo que la mitología se propone contar (1998:483-4).

Pienso que Viveiros de Castro tiene razón de abordar el pensamiento mítico por medio de una metáfora espacial en vez de una, más habitual, metáfora temporal. Aunque es verdad que los relatos míticos amazónicos, insistentemente, se distancian de la vida diaria en términos temporales, los mitos son contados y escuchados durante la vida diaria yine, y por lo tanto, el significado del mito es operativo durante dichas vidas diarias (ver Gow 2001).

En el relato mítico de Artemio, el personaje central se quita la ropa y se convierte en un jaguar. Esto sucede porque la especificación primaria de su cuerpo es como jaguar, el cual es secundariamente especificado como humano, por medio del uso de ropa humana. Como dice Artemio, este mito es el mito de origen de la brujería. A diferencia de la gente "de antes", la gente de "hoy en día" ya no comparte su vida diaria con exitosos muchachos que resultan ser jaguares vestidos de humanos. Pero, si comparten su día a día con hombres mayores que se han convertido en jaguares a través de una re-especificación radical de sus cuerpos. Estos hombres son poderosos chamanes.

Mencioné arriba que, en la actualidad, el uso de "ropa de los antiguos" suscitaba comentarios contrarios, o ridículos. Ahora podemos ver más fácilmente por qué es así. La "ropa de los antiguos", especialmente en su forma fuerte de "ropa nueva de los antiguos", suscita temor, y es de presumir que siempre lo hizo. Por ejemplo, durante un ritual de iniciación femenino al que tuve la oportunidad de asistir, cuando las muchachas aparecieron completamente adornadas, un muchacho se burló diciendo,

¡Parecen mujeres yaminahua!

Los yaminahua son la ejemplificación local de "indios salvajes", ignorantes, atrasados e indómitos.

En ese momento, cuando lo escuché, pensé que la reacción del joven era un tipo de racismo contra sí mismo, y que estaba imitando el desprecio con el que la gente blanca, según él, hubiera reaccionado de haber visto esta escena, patética y atrasada. Después, ya pensándolo bien, comprendí que no podía ser así porque casi siempre la gente blanca se queda estática de admiración ante el poder estético y erótico del momento de la presentación del ritual yine. Ahora creo que el muchacho se burló del temor de su propia reacción ante lo que vio - su, muy probable, futuro como un joven hombre yine, lo llevaría a adentrarse en el bosque para trabajar de maderero, pudiendo verse forzado a entrar en contacto cercano y solitario con verdaderas mujeres yaminahua, y por consecuencia, con sus hombres, gente tan violenta e impredecible como los jaguares. 


\section{Kajine, Gente Blanca}

Ahora que hemos visto que los yine tienen, y presumiblemente siempre han tenido, una relación ambivalente con lo que nosotros vemos como su ropa tradicional, estamos más cerca de una explicación de por qué los yine usan "ropa de gente blanca". Los yine cuentan su propia historia reciente como la historia del decaimiento de lo que los hacía mutualmente temibles. Esta es la fuerza de la historia de Artemio, y es un tema que se encuentra en todos los relatos yine del pasado. A continuación, Juan Sebastián Pérez, un importante líder yine, hace unos comentarios sobre la "vida presente de los yine" al dirigirse a los niños de escuela yine.

En esos tiempos pasados, los piros no nos vestíamos con ropas como las que usan los blancos, sino con ropas hechas a mano. Los hombres usaban cushma y las mujeres una pampanilla dibujada del mismo modo lo era la cushma de los hombres.

Siempre se cazaban animales, aves y peces con flechas. En esos tiempos habian hombre: cazadores por naturaleza y otros adquirían esa habilidad al tratarse con ciertas hierbas. Ahora en 1968, estamos olvidando cazar con flechas. Nos hemos acostumbrado solo a los implementos de los blancos: la tarrafa y la escopeta. Ya se ha perdido la puntería de la flecha. La vida espiritual de los piro también ha cambiado. Antes, eran a brujos a quienes se temian y a los niños se les decía: "cuidado no vayáis a hablar ni reírse. No os riáis del brujo o él va a maldeciros y vais a morir". Pero ahora, no es al brujo, sin: a Dios a quien se teme y se adora. Ahora, sólo hay unos pocos que temen a los brujos (Pérez et al. 1974: 179-85).

Para Sebastián, estos tres cambios están íntimamente entrelazados, y todos implican la pérdida de una forma poderosa de conocimiento (tejer y pintar, buen uso del arco, y brujería) y su reemplazo por "cosas de la gente blanca" (ropa dt gente blanca, instrumentos de gente blanca, y el verdadero conocimiento de dios la gente blanca). Cabe anotar que todas estas manifestaciones de "conocimientos la gente blanca" son abierta y colectivamente disponibles para los yine. Este no ese caso para el conocimiento del tejido y del buen uso del arco, que, como Sebasta indica en el mismo texto, son conocimientos difíciles de adquirir y distribuidos manera desigual entre los yine. El conocimiento de la brujería, sobre el que Sebasti: se mantiene silencioso, sigue la misma lógica.

A finales del siglo $X X$, la idea que los yine tenían sobre la transformación sus relaciones con la gente blanca ocupaba un lugar central en el sentido que atribuían a la "ropa de gente blanca". Me contaron que, hace tiempo, los yine vivían en poblados sino en grupos mutualmente hostiles y endógamos, disp en el bosque, llamados neru. "Vivían peleando y odiándose los unos a los otros" dijeron. Después, fueron esclavizados por los patrones caucheros y fueron a en los poblados de la gente blanca. Ahí, los neru se casaron entre ellos y se cre parentela. Las relaciones con los patrones eran violentas y explotadoras, pero paso del tiempo los yine fueron adquiriendo más y más conocimiento para 
lidiar de manera más igualitaria con la gente blanca, hasta el punto en que, como dicen, se "libraron de la esclavitud", y establecieron sus propios poblados independientes, y comenzaron a vivir los tipos de vida descritos por Sebastián.

Un tema clave de la historia de la transformación de las relaciones de los yine con la gente blanca, es el acceso a la "ropa de la gente blanca". Un tema constante en los relatos de las antiguas relaciones de explotación es cuánto los yine sufrieron para adquirir dicha ropa. A seguir, Morán Zumaeta, describe en 1948, a su antiguo pariente Sangama:

Entonces dijo, 'Miren. Así es como queremos ser. Yo soy asíahora. No uso pantalones, ni camisa. Nunca lo hago. Nunca me has visto usando pantalones, los pantalones y las camisas de los blancos. Pero soy muy rico, porque tengo hijos sanos. Siempre me comporto como una persona pobre aquí, usando estos vestidos, esta cushma, esta ropa", dijo (Matteson 1965:222-3)

Y a continuación, en 1988, Jorge Manchinari, contando el comienzo de su vida en la hacienda de Sepa

Vargas nos trataba muy mal, trabajábamos para él todo el tiempo y no nos daba nunca nada. Cuando era joven, mi padre se ha muerto y Vargas ha dicho que debía pagar las deudas de mi padre. ¿Pero, qué deuda era esa, si nunca nos ha dado nada? Yo me he escapado de ahí, y me he ido río abajo al Bajo Ucayali. Ahi abajo, recién he conocido ropa por primera vez. Trabajando ahí, me he acostumbrado a los pantalones y las camisas. ¡Cuando hemos vivido con Vargas, él nunca nos ha dado nada!

Los problemas encontrados al principio para adquirir ropa de gente blanca, causados por la mezquindad de los patrones blancos, contrastan con la abundancia actual de dicha ropa. Las tiendas de Sepahua y Atalaya están llenas de ropa, y el único problema hoy en día es encontrar el dinero para comprarla.

¿Pero por qué era tan importante para los yine adquirir la ropa de la gente blanca? A mi parecer, hay dos razones interconectadas. Primero, la adquisición de la ropa de gente blanca era una manifestación muy visible del estado de las relaciones entre los yine y la gente blanca. Como hemos visto, la ropa es importante para los yine, y es, en efecto, su prototipo del objeto poseído. Por lo tanto, no es sorprendente que ellos enfocaran la transformación de su relación con la gente blanca sobre la adquisición de su objeto poseído prototípico: su ropa.

La segunda razón reside en la semejanza subyacente entre la "ropa de los antiguos" y la "ropa de la gente blanca". La "ropa de los antiguos", así como la "ropa de gente blanca", es la adquisición de un afecto-jaguar, y un instrumento de intimidación. Así como los jaguares, la gente blanca también es violenta, peligrosa y temible, de tal manera que un afecto-gente blanca puede realizar las mismas funciones que el afecto-jaguar de la "ropa de los antiguos" solía realizar en el pasado: 
en la actualidad, las formas más elaboradas de "actuar como gente blanca", y la mayor cercanía a la gente blanca (kajitu pixkalutu), se da durante los rituales yine contemporáneos. Hoy en día, en las fiestas hombres y mujeres llevan puesta su mejor ropa nueva, mientras que en la vida diaria, así como antes, usan una versión desgastada de su vestido ritual. En las fiestas de hoy, los yine se ven y actúan como gente blanca, pero es crucial subrayar que solamente hacen esto durante los rituales. Ellos no son kajitutachrine, "gente que acostumbra actuar como gente blanca": durante la vida diaria, se ven y actúan como yine.

Este punto me lleva a otro. Cuando vemos a los yine atareados en sus vidas diarias, los vemos con la forma desgastada de su cuerpo ritual amplificado. Virtualmente, toda la ropa que usan diariamente fue originalmente comprada para ser un adorno ritual, y después fue transformada en vestimenta diaria por el uso y el lavado repetidos. Llegados a este punto, podemos regresar a la observación de Matthiessen. Cuando visitó Sepahua en 1961, él vio a gente yine que "no llevan puestas sus ropas tribales". Ahora vemos de manera importante, Matthiessen estaba equivocado: ellos si estaban con vestido tribal, porque esa ropa diaria que llevaban puesta era la transformación en marcha de la ropa usada durante sus acontecimientos rituales en esa época. Entonces, sugerimos que las observaciones de Matthiessen documentan, más correctamente, no la pérdida del vestido tribal, sino la transformación de la vida ritual yine, partiendo del uso de un afecto-jaguar en los contextos rituales antiguos hasta llegar al uso de un afecto-gente blanca en los contextos rituales de las últimas décadas. El hecho que Matthiessen vio a los yine como gente que "no llevaba puesta sus ropas tribales", es simplemente un registro de las relaciones en las últimas décadas de los yine para con sus vidas rituales y para con sus transformaciones en marcha.

\section{Un abordaje histórico del problema}

El acercamiento esbozado arriba no es un estudio histórico en el sentido convencional. Es, más bien, un estudio de lo que los yine me contaron sobre su pasado, lo cual, como sostengo en otro artículo, no es igual a lo que una investigación propiamente histórica, usando fuentes escritas y otros registros del pasado, podría sacar a relucir sobre el pasado yine (Gow 1991, 2001). Si que es que abordamos el estudio de los cambios en el vestir yine desde el punto de vista de las fuentes propiamente históricas disponibles, entonces podríamos preguntarnos cómo es que los cambios establecidos por este análisis histórico propiamente dicho, pueden ser relacionados a los cambios establecidos por el análisis de lo que los vine me contaron sobre su pasado que he desarrollado arriba. Es lo que paso a hacer a continuación.

Aunque los yine hablan sin más sobre la "ropa de la gente blanca" y la "ropa de los yine", los dos estilos son históricamente complejos. Podemos trazar las transformaciones de los estilos de vestir yine a lo largo de los siglos XIX y XX con cierta 
precisión, utilizando las descripciones y los dibujos o fotografías de los yine hechos por misioneros, viajeros y antropólogos. Hago un resumen de esta evidencia aquí.

Hasta la mitad del siglo $X X$, los hombres y las mujeres yine solían usar la ropa que llamaban mkalu, "túnica de algodón" y mkalnama, "túnica de vagina" (ver Marcoy 1875). Al final del siglo XIX, empezaron a adoptar el estilo que llamaré de cristiano, debido a la designación de la gente que lo usaba originalmente. Estos eran indígenas del norte de la amazonía peruana que habían permanecido bajo la influencia de las misiones jesuitas y franciscanas durante largo tiempo, gente como los jebero, los cocama-cocamilla y los quichua lamista. A lo largo del siglo XIX, los yine del Urubamba tuvieron cada vez mayor contacto con estos cristianos, adoptando su estilo de vestir. Samanez y Ocampo informan sobre la situación del vestir yine en 1883-4:

Visten pantalón y camisa, o camiseta de punto; y usan sombrero de paja, o gorra, que les traen los comerciantes. Usan también el saco, su traje primitivo, que les acomoda más cuando trabajan como bogas, por la facilidad de desnudarse, ya para halar las canoas en las corrientes o para bañarse, lo que hacen cuatro o cinco veces al día.

Las mujeres no tienen más vestido que la pampanilla, especie de tonelete que les cubre por delante, desde debajo del ombligo hasta media pierna y por detrás de la cintura a las corbas. En lugar de la mantita que acostumbraban antes para cubrirse la espalda y los costados, llevan ahora un saquito o camisa, que apenas les llega a la cintura y encima del ombligo. Un gran cinturón de innumerables hilos de chaquira blanca y collares de granates, o avalorios de diversos colores, combinados con gusto, completan su sencillo vestido.

También los hombres llevan por corbata, sayuelos de chaquira fina de diversos colores, muy bien tejidos, trabajo que hacen las mujeres. La costumbre de pintarse la cara, manos y piernas, es universal, desplegando en ello rara habilidad: dibujan a pulso adornos del mejor gusto y admirable simetría. El tinte de que se sirven es del fruto del huito, que da un color negro azulado. Sólo en caso de guerra se pintan de rojo, usando para ello achiote (Samanez y Ocampo 1980:66-7).

Farabee también publicó fotografías de gente yine vestida en este estilo, tomadas en 1907 (1922). Cabe subrayar, sin embargo, que el estilo de vestir cristiano no es, obviamente, "ropa de gente blanca" en el sentido de Matthiessen. Es una combinación transformacional del estilo de vestir antiguo con elementos del nuevo estilo cristiano. Lo que es cierto, es que no es como se vestía la gente blanca con la que los yine estaban en contacto en ese momento (es decir, la gente que interactuaba con los yine y que se identificaba como "gente blanca"). La gente blanca rica de la época, vestía principalmente ropa de estilo brasilero, es decir, ropa comprada en Europa.

Como lo indican claramente la nota de Samanez y Ocampo y los registros visuales de la época, los yine adoptaron su estilo de vestir cristiano a partir de una 
combinación transformada de su antiguo estilo de vestir y del estilo de los cristianos. Las antiguas túnicas y faldas tejidas de algodón continuaron siendo usadas de manera diaria, pero en combinación con pantalones y camisas para hombres, y blusas para mujeres. La adopción del estilo cristiano tuvo por consecuencia que los yine tuvieran que emprender relaciones de intercambio para conseguir su nueva ropa. Al contrario del antiguo estilo, hecho de tela de algodón, los nuevos pantalones y camisas de los hombres, y las blusas de las mujeres, sólo podían ser hechos de tela de tocuyo comercial. Mientras los elementos necesarios para el antiguo estilo de vestir podían ser hechos por uno mismo o conseguidos por medio del intercambiado, o del robo, con personas tejedoras, el nuevo estilo hacía obligatoria la adquisición de tocuyo comercial.

En la década de 1940, el estilo cristiano fue abandonado virtualmente en masse, y reemplazado por un otro nuevo estilo (ver Matteson 1954). Lo llamo de estilo mozo. Los que crearon este estilo eran básicamente los descendientes de los cristianos, quienes durante el periodo de una generación transformaron su auto-identificación y su estilo de ropa. El rasgo principal de este estilo es el casi abandono de la ropa tejida a mano a favor de la ropa hecha con tela producida y adquirida comercialment: Para los hombres, esto implicó el abandono de la túnica de algodón. Para las mujeres la transformación fue más dramática, porque abandonaron tanto la falda tejida como la blusa calico, para adoptar vestidos estampados de algodón.

Este estilo mozo permaneció hasta las décadas de 1970 y 1980, cuando los yine lo abandonaron a su vez para adoptar lo que llamo de estilo mestizo. Los mestizos son, una vez más, básicamente los cristiano - mozos nuevamente transformados. El estilo de vestir mestizo se basa en la compra de ropa lista parz usar en las tiendas de A talaya y Sepahua. Esencialmente, consiste en camisas y polos con pantalones y shorts para los hombres, y blusas y polos con faldas y bermudas el decaimiento del uso de vestidos, para las mujeres. Aunque la ropa es producit en masa en la costa del Perú, este estilo mestizo es muy distintivo de la amazon peruana, y no se encuentra en otros lugares del Perút. Y, a pesar de la llegada muchos inmigrantes de los andes al lugar, no ha habido ningún movimiento adopción del estilo de vestir andino por parte de los yine. Al contrario, actualmente cada vez más, los inmigrantes andinos están utilizando el estilo mestizo.

Hay que hacer dos aclaraciones sobre estos datos históricos. Primero, vecinos inmediatos al norte de los yine, los konibo, han seguido un camino de camb. muy diferente. Desde 1940, las mujeres konibo han mantenido la dirección hacie una intensificación dramática del estilo cristiano. Las faldas tejidas a mano han sta abandonadas, pero han sido reemplazadas por faldas hechas con máquinas de cose a pedales. Al mismo tiempo, ha habido una explosión en la complejidad del dise'y la construcción de las blusas. Dada las semejanzas generales entre las condicione

El estilo de vestir de la Amazonía brasilera es una de las mayores influencias estilísticas si los estilos de vestir en la Amazonía peruana. 
de los yine y los konibo, a mi parecer, no hay ninguna razón obvia por la que deberían de haber seguido caminos tan diferentes.

Segundo, los cambios de estilo yine muestran de manera consistente las transformaciones de vestir de un grupo de gente, los cristianos - mozos, como parte del proceso de transformación de sus auto-identificaciones a lo largo del tiempo. Por esta razón, a pesar de lo que Matthiesen (y yo mismo, a este respecto) pensemos que pasó, y a pesar de lo que los propio yine dicen que pasó, los yine no usan "ropa de blancos" propiamente dicha, en la medida en que no utilizan la ropa que la gente local que se auto-identifica como "gente blanca" utiliza. Ellos se visten con el estilo de ropa de los cristianos - mozos - mestizos, y hacen esto sea cual sea el medio por el que adquieren sus ropas.

En ciertas circunstancias, los yine definen a los cristianos - mozos -mestizos, como kajine, "gente blanca", en oposición a ellos mismos, yine, "humanos". En este sentido, los yine afirman correctamente que visten kajitu mkalu, "ropa de gente blanca". Pero, aunque llamen a los cristianos - mozos - mestizos de kajine, no los consideran ser el mejor, o el más fuerte, ejemplar de la categoría kajine potu. Para los yine, la "gente blanca legítima" no son los cristianos - mozos - mestizos sino los patrones blancos y ricos, es decir, unas personas que niegan tener cualquier tipo de lazo de descendencia con los pueblos indígenas amazónicos y que, en cambio, asegura descender de los inmigrantes en la región. Cuando los yine hablan sobre la kajitu mkalu, la "ropa de gente blanca" que aspiran a poseer, queda claro que se refieren a la ropa de esa "gente blanca legítima", y no la de los cristianos-mozos-mestizos. Es decir, aunque históricamente los estilos de vestir yine se originaron de estos últimos, los yine identifican sus estilos de vestir con la "gente blanca legítima".

Los esquemas de transformación de estilos de vestir descritos aquí son probablemente muy antiguos. A pesar de que los yine han vivido en el bajo Urubamba por lo menos desde el tiempo de las primeras crónicas históricas, es casi seguro que vinieron del este y que adquirieron el vestir cuando llegaron a la cuenca del Ucayali. En particular, es muy probable que adquirieron su estilo "tradicional" cuando entraron en contacto con las redes de intercambio del sudeste peruano, muy probablemente de los konibo o cocama. Esta hipótesis recibe evidencias en confirmación de dos líneas de argumentación. Primero, los parientes lingüísticos más cercanos de los yine, los apurinã del Brasil occidental, de quienes los yine probablemente se separaron hace unos ocho siglos, no utilizaban esta ropa. Segundo, en las lenguas emparentadas al yine, la raíz de la palabra ropa, -mka, es la raíz de "dormir" y de "hamaca". En otro artículo he mostrado que los ancestros de los yine migraron del este hacia lo que hoy en día es el Perú, abandonando el uso de hamacas y adoptando el estilo de vestir de la gente local, de tal manera que durante este proceso la palabra que significaba "hamaca" migró semánticamente hasta denotar el nuevo ámbito de "vestir" (Gow 2002). 
Esta perspectiva histórica tiene dos consecuencias importantes. Primero, sugiero que la manera en que los yine piensan sobre la ropa, como algo que señala la alteridad (ya sea la de los jaguares o la de la gente blanca), es históricamente operativa. Los yine continuamente toman la ropa de otros seres, hasta cuando estos seres no son los jaguares ni la gente blanca de sus categorías concientes, sino sus vecinos del norte, los konibo, cocama y otros pueblos. En efecto, se podría decir que la transformación de los estilos yine de vestir es la evidencia de un largo proceso de emulación de los cocama, quienes, históricamente, constituyen el componente de población más importante de los cristianos-mozos-mestizos en la región.

Segundo, y tal vez de mayor importancia teórica, este análisis sugiere que L "aculturación", un fenómeno de significado tan directo y obvio para observadores occidentales como Matthiessen y yo mismo, puede que sea un fenómeno real, per de un orden muy diferente al usualmente supuesto. Sugiero que la "aculturación" a una concepción indígena amazónica sobre los procesos históricos en marcha. Hace tiempo, Lévi-Strauss señaló que, para los pueblos amazónicos, la guerra y el intercambio eran los dos lados de una misma relación para con el otro, sus caras violenta y pacífica, podríamos decir (1976 (1942)). Por lo tanto, no es de sorprender que la apacibilidad para con el otro esté marcada por un ávido deseo de obtener los objetos y los conocimientos del otro, puesto que lo que está por ganarse, o po: perderse, es una relación social (Hugh-jones 1992). Pero, lo que los pueblos amazónicos no están queriendo adquirir es la "cultura" del otro, porque la "cultura" según Viveiros de Castro, es ajena a sus cosmologías perspectivistas. La "aculturación" es, por lo tanto, una descripción literal superficial de las cosmologías perspectivistas en acción histórica.

\section{La modernidad como una perspectiva amazónica}

En este artículo, no he intentado colocar a los yine dentro de la modernidad ni etnográfica ni históricamente. En cambio, he tratado de situar una respuesta estética modernista hacia los estilos de vestir yine, la de Matthiessen y mía, dentro de un contexto etnográfico e histórico específico. Esto es, por su puesto, lo que se espera que hagan los antropólogos, pero, inevitablemente, siempre parece ser totalmente inadecuado. La modernidad como fenómeno no se encuentra solamente en Sepahua en 1961, o en el bajo Urubamba en la década de 1980, sino en todas partes. Sus expresiones locales se ven ocultas por su ubicuidad. En conclusión, quisiera regresar brevemente a la localidad etnográfica e histórica de la "modernidad", en la especificidad local de las reacciones estéticas de gente como Matthiessen y mi persona.

La modernidad como concepto implica necesariamente una tradición a la cual oponerse, una tradición que es necesariamente concebida como tradicional. Es decir, la tradición es figurada como algo que debería ser transmitido de generación en generación sin cambiar. Es más, estas tradiciones son vistas como siendo muchas, 
mientras la modernidad es concebida como si fuese una sola. Cuando Matthiessen describe a los pobladores indígenas de Sepahua, ese "bando mixto de piros, amahuacas y machiguengas", no necesita decirnos lo que sus ropas tradicionales podrían haber sido. Basta que Matthiessen, y sus lectores, hablen de esta diversidad de pueblos para que sea evidente que debían tener, o haber tenido, diversas tradiciones, y por lo tanto formas tradicionales de vestir. Igualmente, los pueblos indígenas que viven en áreas más remotas, con "su cabello largo y pintado", no plantean ningún problema histórico significativo porque mantienen su tradición y su diversidad. Estas ideas son autoevidentes en la medida en que se dan dentro de la estética modernista.

Dicha auto-evidencia, sin embargo, comienza a resquebrajarse precisamente cuando comenzamos a preguntarnos qué es lo que esta ropa podría significar para los propios pueblos indígenas. Como he mostrado en otro artículo, los yine no conciben a su ropa en términos de una diversidad tradicional opuesta a una modernidad singular. Las cosmologías perspectivistas no piensan en la "tradición" de esta manera. Lo que les interesa es la diversidad de las perspectivas, pero las perspectivas no son tradicionales porque transmitir una perspectiva de padre a hijo no significa nada. Las cosmologías perspectivistas no pueden, por lo tanto, encarar a la modernidad como si ésta fuese un desafío a la tradición, sino solamente como una otra perspectiva. Por esto, lo que les interesa a los yine no es la modernidad como tal, sino el hecho que la modernidad le interese a los que ellos llaman kajine, "gente blanca". Los yine se ven "modernos" ante nuestros ojos porque ellos quieren verse como kajine, no porque valoren a la modernidad ni porque la opongan a una tradición a la que supuestamente hubieran dejado atrás. En efecto, aunque hubiésemos comenzado por aceptar la idea de que existe una "cultura tradicional yine", nos hubiéramos vistos forzados a llegar a la misma conclusión, porque hubiéramos rápidamente descubierto que esta supuesta "cultura tradicional yine" está hecha de todas las ideas sobre perspectivas que he expuesto arriba.

Finalmente, regreso a la reacción estética con la que comencé: ¿por qué es que, uno tras otro, y con una regularidad deprimente, los pueblos amazónicos abandonan sus artes corporales tradicionales para adoptar la ropa occidental? Esta aparente uniformidad, sugiero, no es una demostración de la uniforme fragilidad de las sociedades indígenas amazónicas ante la presencia de la modernidad. En cambio, es un registro del hecho histórico contingente que las sociedades indígenas amazónicas están lidiando con una perspectiva que, como ninguna otra, se imagina a sí misma como si fuese una perspectiva unificada y transferible, pudiendo ser tomada por cualquiera. Esta perspectiva se llama a sí misma "modernidad". Significativamente, sin embargo, este mismo fenómeno banal presente en toda la Amazonía revela un rasgo inesperado de dicha modernidad: los pueblos indígenas amazónicos pueden, y de hecho lo hacen, usar la modernidad para explorar las implicancias y los potenciales inesperados del perspectivismo. 


\section{Agradecimientos}

Mi trabajo de campo en el Bajo Urubamba y en Acre entre 1980 y 2001 fue financiado por el Social Science Research Council, el British Museum, la Nuffield Foundation, la British Academy y la London School of Economics. Le agradezco a Michael O'Hanlon y a Elizabeth Ewart por su invitación a la conferencia, y a todos los participantes por sus comentarios sobre la versión original. También quiero agradecer a Ben Campbell, Jeanette Edwards, Marcio Goldman, Tânia Stolze Lima, Maire Mayne, Christina Toren y Eduardo Viveiros de Castro por sus preguntas, comentarios y sugerencias.

\section{Bibliografía}

Farabee, William Curtis

1922 Indian Tribes of Eastern Peru, Papers of the Peabody Museum of Archaeology and Ethnology, Harvard University, Volumen 10, Cambridge Mass.: Harvard University Press.

Gombrich, Ernst H.

1960 Art and Illusion: A Study in the Psychology of Pictorial Representation, Oxford: Phaidon.

Gow, Peter

1991 Of Mixed Blood: Kinship and History in Peruvian Amazonia, Oxford Studies in Social and Cultural Anthropology, Oxford University Press.

2001 An Amazonian Myth and its History, Oxford University Press.

2002 Piro, Apurinã and Campa: Social Dissimilation and Assimilation in Southwestern Amazonia. Jonathan D. Hill and Fernando Santos-Granero (eds) Comparative Arawakan Histories: Rethinking Language Family and Culture Area in Amazonia, pp.147-170, Urbana and Chicago: University of Illinois Press. 
Hugh-Jones, Stephen

1992 Yesterday's luxuries, tomorrow's necessities; business and barter in northwest Amazonia. Caroline Humphrey and Stephen Hugh-Jones (eds.) Barter, Exchange and Value: An anthropological approach, Cambridge: Cambridge University Press.

Lévi-Strauss, Claude

1976 Guerra e comércio entre os índios da América do Sul. Egon Schaden (ed.) Leituras de Etnologia Brasileira, Sao Paulo [original, 1942].

1995 The Story of Lynx, Chicago and London: University of Chicago Press.

Lima, Tânia Stolze

1999 The two and its many: Reflections on perspectivism in a Tupi cosmology. Ethnos, 64(1):107-131.

Marcoy, Paul

1875 Travels in South America from the Pacific Ocean to the Atlantic Ocean, (2 Vols.) London: Blackie.

Matteson, Esther

1954 The Piro of the Urubamba. Kroeber Anthropological Society Papers 10: 25-99.

1965 The Piro (Arawakan) Language, Berkeley and Los Angeles: University of California Press.

Matthiessen, Peter

1962 The Cloud Forest: a chronicle of the South American Wilderness, London: André Deutsh.

Nies, Joyce, (comp.)

1986 Diccionario Piro (Tokanchi gikshijikowaka-steno), Serie Lingüística Peruana 22. Yarinacocha: Ministerio de Educación and Instituto Lingüístico de Verano.

Rivière, Peter

1994 WYSINWYG in Amazonia. Journal of the Anthropological Society of Oxford, 25(3):255-62.

Samanez y Ocampo, José B.

1980 Exploración de los Ríos Peruanos, Apurímac, Eni, Ucayali y Urubamba, hecho por Samanez y Ocampo en 1883 y 1884, Lima: impresión privada.

Sebastián Pérez E., Juan; Morán Zumaeta B.; and Joyce Nies

1974 Yine pirana 12: Gwacha ginkakle (Cartilla de lectura 12: Historia de los piros). Lima: Ministerio de Educación. 


\section{Veber, Hanne}

1996 External Inducement and Non-Westernization in the Uses of the Ashéninka Cushma. En The Journal of Material Culture, 1(2):155-182

Viveiros de Castro, Eduardo

1998 Cosmological Deixis and Amerindian Perspectivism. Journal of the Royal Anthropological Institute, (N.S.) 4:469-88.

2001 Gut Feelings about Amazonia: Potential Affinity and the Construction of Sociality. Laura Rival and Neil Whitehead (eds) Beyond the Visible and the Material: The Amerindianization of Society in the zoork of Peter Rivière, pp. 19-43 Oxford: Oxford University Press. 